\title{
Relationship between Students' Scores on Plain Questions and Worded Problems in Mathematics
}

\author{
Ossai Peter Agbadobi Uloku \\ Department of Guidance and Counselling, \\ Delta State University, Abraka. Nigeria
}

Doi: 10.36941/jesr-2020-0052

\begin{abstract}
It appears that students find it easier to solve problems on plain questions than worded problems in mathematics. This led the researcher to study the relationship between students' scores on plain questions and their scores on worded problems. The study was correlational. A sample of 122 final year senior secondary school students was drawn through judgemental sampling technique from public secondary schools in Bayelsa and Delta states, south-south Nigeria. The instrument had five plain questions and five worded problems adapted from the May/June West African Senior School Certificate Examination questions examined in 2009,2010 and 2011. Students responded to questions in algebraic operations, arithmetic, trigonometry and geometry. Using mean and the product moment correlation statistics to analyze the scores from the two set of questions, it was discovered that scores from plain questions had no significant relationship with scores from worded problems. However, students had higher mean score on plain questions. It was recommended that students should be drilled in solving word problems in mathematics.
\end{abstract}

Keywords: Relationship, Mathematics, scores, plain, worded, questions

\section{Introduction}

Nigeria is in the quest for scientific and technological development. This feat cannot be achieved outside sound education. In particular, there can be no break-through in science and technology without mathematics. Besides its significant role in nation building, mathematics helps in shaping the way people deal with the various spheres of private, social and civil life, Anthony and Walshaw (2009), as cited by Mensan, Okyere and Kuranchie (2013). The national Policy on Education (2004) specifies the status of mathematics as a core subject which must be offered by pupils and students at the primary and post-primary levels of education across the country. This status of mathematics must have informed the inclusion of the subject on school's time-table as a subject to be taken every day.

Although, mathematics plays a significant role in the scientific and technological development of a nation, the performance of students does not justify the place of the subject in nation building. The West African Examinations Council Chief Examiners (2011) reported that candidates who recorded credit passes and above in mathematics have not been more than $40 \%$ of the total number of candidates that wrote the examination from 2009 to 2011. This suggests that there will be a great reduction in the number of applicants seeking admission into Universities and other institutions of higher learning in and outside the country. This is because mathematics is a compulsory requirement in many courses. 
The poor trend in students' performance in mathematics appears not be limited to Nigeria. In Ghana, Chief Examiners' 2007 report, cited by Mensah, et al. (2013) showed that candidates demonstrated poor understanding of mathematics concepts, and this led to inability to form the necessary mathematical models to be tackled with the requisite skills.

The experience of this researcher as a secondary school mathematics teacher from 1993 to 2007, and as a part-time course tutor at the National Teachers' Institute (NTI/DLS) from 2004 till date, shows that the problems militating against students in mathematics rest greatly on word problems. Most students appear to have dislike for worded problems in mathematics. Take for instance, this question from Macrae et al. (2002): "The ages of a parent and child add up to 39 years. In 5 years the parent will be 4 times as old as the child. Find the ages of the parent and the child", (p. 113). This problem can easily be tackled by assuming the ages of the parent and child to be $\mathrm{x}$ and $\mathrm{y}$, respectively. Thus, making $x+y$ equal to 39. The second sentence translates to $x+3=4(y+3)$. This simplifies to $x$ $-4 y=9$. Hence, the two equations to be solved simultaneously are $x+y=39$ and $x-4 y=9$. If the two linear equations are presented in plain form for students to solve, the task will be very easy. However, this is not the case when the problem is presented in word form as shown. The same thing may apply to the item couched by WAEC (2010) as follows: the sum of 2 consecutive whole numbers is $\frac{5}{6}$ of their product. Find the numbers. Here, test-takers will be confronted with words like "consecutive" and "product" before arriving at $\mathrm{x}+(\mathrm{x}-1)=\frac{5}{6}$ of $\mathrm{x}(\mathrm{x}+1)$ producing $5 \mathrm{x}^{2}-7 \mathrm{x}-6=0$. The test-taker will face the problem of dropping one of the roots of the equation $\left(x=\frac{3}{5}\right)$ since only whole numbers are required. Given this equation, little or no challenge is posed.

Some researchers have conducted some studies concerning word problems in mathematics and students' mathematics achievement. Bates and Wiest (2004) conducted a study on "Impact of personalization of mathematical word problems on student performance." A sample of 42 students (22 boys and 20 girls) was drawn from a population of fourth-grade students at Copper Flats Elementary School in Northern Nevada. A quantitative analysis of the effects of personalizing word problems on fourth-grade students' achievement was used. Ten problems were randomly selected from a mathematics textbook with which the students were familiar. Five problems were personalized while 5 were not. Using a paired samples t-test to compare the two sets of problems, in addition to descriptive statistics of mean and standard deviation, the study revealed that there was no significant increase in student achievement when the personalization treatment was used regardless of student reading ability or word problem type. The researchers concluded that this result may be attributed to the tender age of the subjects used for the study. They asserted that personalization of word problems in mathematics may be useful in teaching older students.

Kurumeh and Chiawa (2009) carried out a study on "Impact of Students' Interest in Solving Algebraic Word Problems Using Aesthetic Value Approach". A sample of 240 SS 1 students was randomly drawn from six intact classes from three co-educational secondary schools in Makurdi LGA of Benue State. The study which was quasi-experimental used a non-equivalent pretest, posttest control group design. An interest inventory and two lesson plans were used in the study. The hypotheses were tested using AWPSII while mean and standard deviations were employed in answering the research questions. The major finding of the study was that students taught algebraic word problems using Aesthetic Value Approach showed significantly higher interest than those taught the same topics with conventional methods. This present researcher feels that the result is a pointer to the fact that new ways of doing things are likely to produce better results.

Other researches on word problems and mathematics were conducted by Sepeng and Madzorera (2014) and Esan (2015). Sepeng and Moadzorera (2014) studied "Sources of Difficulty in Comprehending and Solving Mathematical Word Problems" using mixed - methods design. A sample of 60 subjects ( 29 females and 31 males) was drawn from Grade II learners taking mathematics in a township high school through purposive sampling. A test of word problems and a questionnaire were administered to the Grade II learners. Data analysis was performed using the analytic frameworks of 
Garegae (2007) and Latu (2004), as cited by Sepeng and Madzorera (2014). The study revealed that Mathematical language appeared to influence learners' comprehension when solving mathematical word problems. The study of Esan (2015) centered on "Co-operative Problem - Solving Strategy and Students' Learning Outcomes in Algebraic Word Problems: A Nigerian Case.” A sample of 240 Junior Secondary School Students was randomly drawn from six schools in Ilesa Local Government Area of Oshun State in Nigeria. The six schools were randomly assigned to control and experimental groups. The Experimental Group was taught algebraic word problems using Co-operative Problems-Solving Strategy (CPS) while the Control Group was taught using conventional teaching methods. A 16-item questionnaire and 20 item multiple choice achievement tests on algebraic word problems were administered to the participants. The two groups were post-tested at the end of the fourth week. Using a t-test statistics, the result indicated that the overall achievement of students exposed to (CPS) was better than those exposed to the conventional methods. The researcher recommended the inclusion of the (CPS) in training mathematics teacher.

The review of the empirical studies seems to suggest that learners of mathematics have to fully understand mathematics words before meaningful solutions can be provided. Besides mathematics vocabulary, the ordinary meaning of words in English Language may be helpful. By way of analogy, phrases or words such as "at least" "at most", "inclusive", "respectively" "regular" and "at random" commonly found in mathematics word problems require an understanding of the dictionary learning, besides their special meanings in mathematics vocabulary/register. The understanding of the two is crucial and may lead to a successful attempt at word problems in mathematics. On the other hand, the inability of students to understand the dictionary meaning and the specialized usage of these words may result in item differential functioning. In other words, the items couched are not unidimensional (do, not measure a single latent trait in mathematics).

This study seeks to compare the achievement of students in plain Mathematics problems and word problems in Mathematics. This appears not to have been covered by researchers, to the best knowledge of the present researcher.

\section{Statement of the Problem}

Mathematics is crucial to advancement in science and technology. The emphasis given to Mathematics at the primary and post-primary levels of education in Nigeria has prompted governments at all levels and other stakeholders in the education industry to encourage the study of the subject by providing the necessary resources. The poor performance of students seems not to justify the attention being given to Mathematics. Majority of our secondary school students cannot solve simple problems in Mathematics. The situation becomes worse when such students are made to solve simple word problems in Mathematics. This is simple application of what has been taught.

Not only is it important for students to learn Mathematics concepts, it is also needful that students should be able to relate Mathematics to real life situations. The problem for this study is "What is, the relationship between students' scores on plain Mathematics questions and scores on word problems in Mathematics?"

\section{Research Questions}

The following research questions guided the study:

1. What are the mean scores for plain questions and worded questions?

2. What is the extent of relationship between students' scores on plain questions and scores on worded questions?

\section{Hypothesis}

The following hypothesis was tested at .o5 level of significance: 
1. There is no significant relationship between students' scores on plain questions and scores on worded problems in mathematics.

\section{Methodology}

The study used a descriptive correlation survey design. The population consists of final year students from selected public Senior Secondary Schools in Bayelsa and Delta States. These states are both in Nigeria's south-south geopolitical zone. Judgmental sampling technique was employed in drawing a sample of 122 students for the study. The instrument used in the study was ten mathematics questions (five plain questions and five word problems). The questions were adapted from the May/June West African Senior School Certificate Examination (WASSCE) General Mathematics/ Mathematics (Core) 1 for 2009, 2010 and 2011. The areas covered were arithmetic, algebra, statistics, trigonometry and geometry. Respondents were provided with plain answer sheets for solutions to the mathematics items. A time duration of $1^{1 / 2}$ hours was given to the respondents. With the help of some mathematics teachers, the researcher developed a marking scheme having a maximum score of 50 marks (25 marks for the five plain questions, and 25 marks for the five worded problems). The questions carry equal marks. Students' responses were scored by senior mathematics teachers. Each respondent had two sets of scores, one for plain questions and the other for word problems. The resulting scores were subjected to a correlation analysis using the Product Moment Correlation technique at .05 level of significance. The mean and co-efficient of determination were used to answer the research questions.

\section{Data Analysis and Presentation of Results}

\subsection{Research question one: What are the mean scores for plain questions and worded questions?}

Table 1: showing students' mean scores for plain questions and worded questions

\begin{tabular}{lcccc}
\hline Variables & $\mathrm{N}$ & $\overline{\mathrm{X}}$ & SD & Mean Difference \\
\hline Plain Questions & $\mathbf{1 2 2}$ & $\mathbf{1 5 . 3 4}$ & 8.5 & \multirow{4}{*}{4.42} \\
Worded Questions & $\mathbf{1 2 2}$ & 10.92 & 6.7 & \\
\hline
\end{tabular}

Table 1 shows that mean scores were 15.34 and 10.92 for plain questions and worded questions, respectively. The mean difference is 4.42 while the standard deviations are 8.5 and 6.7 for plain questions and worded questions, respectively.

6.2 Research question two: What is the extent of relationship between students' scores on plain questions and scores on worded questions?

Table 2: showing the extent of relationship between students' scores on plain questions and scores on worded questions

\begin{tabular}{lccc}
\hline Variables & $\mathrm{N}$ & $\mathrm{r}$ & $r^{2}$ \\
\hline Plain Questions & $\mathbf{1 2 2}$ & .083 & .0069 \\
Worded Questions & $\mathbf{1 2 2}$ & .083 & \\
\hline
\end{tabular}

Table 2 shows that r-value is 0.83 while the co-efficient of determination is .oo69; this implies that less than $1 \%$ of the ability needed in solving worded problems is due to the knowledge of plain questions. 


\subsection{Hypothesis one}

There is no significant relationship between students' scores on plain questions and scores on worded questions.

Table 3: showing the analysis of the relationship between students' scores on plain questions and worded questions.

\begin{tabular}{lccc}
\hline Variables & $\mathrm{N}$ & $\mathrm{r}$ & Sig. \\
\hline Plain Questions & 122 & \multirow{2}{*}{0.083} & 0.363 \\
Worded Questions & 122 & & \\
\hline
\end{tabular}

From Table 3, the value of $\mathrm{r}$ is 0.083 ; at an alpha level of .05, the p-value is .363; since the p-value is greater than the alpha level, the null hypothesis is retained. Thus, there is no significant relationship between students' scores from plain questions and worded questions.

\section{Discussion of Findings}

Answer to research question one shows that students' mean score in plain questions was higher than their mean score from worded questions. This is expected because there is a general belief by students' that plain questions are easier to solve compared to worded questions. Research question two indicates that there is a possible relationship between the two sets of scores obtained by the students,. It further showed that $r^{2}$, the co-efficient of determination, is .oo7; thus students' ability to solve the worded problems was accountable to less than $1 \%$ of knowledge required to tackle plain questions.

The test of hypothesis further shows that there is no significant relationship between scores on plain questions and scores on worded questions. This result is in spite of the fact that students did better in plain questions. The mean score from plain questions is 4.42 points higher than the mean score from worded questions.

The finding from this study supports the earlier results reported by Sepeng and Madazorera (2014) as well as Esan (2015). According to Sepeng and Madzorera, mathematics language seems to affect the ability of learners to solve worded problems in mathematics. Similarly, Esan (2015) reported that students who were exposed to problem-solving using co-operative problem solving strategy did better than those exposed to the conventional method.

The finding from this study is also in consonance with WAEC Chief Examiner's Report (2007) as cited by Mensah, et al. (2013). The Chief Examiners reported that candidates demonstrated poor knowledge of mathematics concepts which resulted in their inability to form the necessary mathematical models to be tackled with the requisite skills.

The result of this study, however, disagrees with the finding made by Bates and Wiest (2004). These scholars discovered in their study that there was no significant increase in students' achievement when mathematical word problems were personalized. The disagreement is obvious because students' scores in this study were higher in plain questions

The low achievement of the subjects of this study in worded problems seems to suggest that language must have played a major role. Take item one (Section B), for instance; this is just a combination of simple statistics and inequality $\left(\frac{2+5+2 x+7}{4} \leq 5\right)$. If this question were to be in plain form, responses to the item would have been better. Combining knowledge of mean and inequality posed the problem. The same thing applies to item 2 from the same section. Students required knowledge of arithmetic (directed numbers) and simple algebra (factorization of a quadratic expression) to be able to solve the problem. The word "smaller" in the question constituted the problem. Majority of the students could not decide on -5 or -2 ,, the roots of the equation 
$x^{2}+7 x+10=0$. Many of the students either ended their work as $x=-5$ or -2 , or simply concluded that $\mathrm{x}=\mathbf{- 2}$. There was the difficulty in deciding which root was smaller.

This trend is in line with Inweregbuh (2018) who reported that students have difficulty in handling algebraic operations. According to the scholar, many students do not understand the basic principles of algebra. This must have affected the finding of the present study wherein knowledge of algebraic operations was necessary.

\section{Conclusion}

Students have enormous challenges in solving worded problems in mathematics. Although, the mean responses to plain questions and worded problems are not markedly different, students have demonstrated in this study that they are more comfortable with solving plain questions than worded problems.

This trend reflects the position of scholars in literature that students find it difficult to make meaning out of worded problems in mathematics. Thus, very few students are able to make the grades that are necessary to take them to institutions of higher learning. This is capable of affecting the nation's quest for advancement in science and technology negatively.

This study is a pointer to mathematics teachers and other stakeholders in the education industry that students' skills in solving plain questions are not enough to prepare them for adequate solutions to worded problems in mathematics. Thus, students need to acquire mathematics vocabulary to be able to form algebraic expressions or equations from simple worded problems. In other words, mathematics should be related to real life situations.

\section{Recommendations}

In line with the findings and conclusion from this study, the following recommendations were made:

i) Students should be drilled in mathematics vocabulary to keep them abreast with words that are commonly associated with mathematical questions.

ii) Mathematics teachers should take cognizance of the questions that are always avoided by students

\section{References}

Bates, E. T. \& Wiest, L. R. (2004). Impact of personalization of mathematical word problems on student performance. The Mathematics Educator, 14(2), 17- 26.

Chief Examiner's Report, WASSCE (2011). The West African Examinations Council: Lagos.

Esan, F. (2015). Co-operative problem-solving and students' learning outcomes in algebraic word problems. A Nigerian Case. International Journal of Infonomics, 8(1).

General mathematics/mathematics (Core) 1 (2010). The West African Examinations Council: Lagos.

Inweregbuh, O.C (2018). Influence of school categories on the performance of senior secondary school students in algebraic equations in Sokoto state, Nigeria. African Journal of Science, Technology and Mathematics education, 4(1), 118-125.

Kurumeh, M. S. \& Chiawa, M. A. (2009). Improving Students' Interest in Solving Algebraic Word Problems Using Aesthetic Value Approach. Research Journal of Mathematics and Statistics, 1(2), 59 - 64.

Macrae, M.F. et al. (2002) New General Mathematics for Senior Secondary Schools 3. China: Person Education Limited.

Mensah, J. K. et al. (2013). Students attitude towards mathematics and performance: Does the teacher attitude matter? Journal of Education and Practice, 4(3). 133 - 139.

Sepeng, P. \& Madzorera, A. (2014). Sources of difficulty in comprehending and solving mathematical word problems, International Journal of Educational Science, 6(2), 217 - 225. 


\section{Appendix 1}

\section{MATHEMATICS FOR RESEARCH}

Instruction: The following are some mathematics questions designed for research purpose. Please provide detailed solutions that lead to the answers.

\section{ANSWER ALL QUESTIONS}

TIME DURATION: 1 Hour

\section{SECTION A:}

1. Correct .002473 to 3 significant figures.

2. What is the median of the following numbers: $22,41,35,63,82,74$ ?

3. If $27^{x}=9$, find $x$

4. Solve $\frac{2 x+1}{6}-\frac{3 x-1}{4}=0$

5. Factorize the expression $\mathrm{am}+\mathrm{bn}-\mathrm{an}-\mathrm{bm}$.

\section{SECTION B:}

1. The mean of the numbers $2,5,2 \mathrm{x}$ and 7 is less than or equal to 5 . Find the range of value of $\mathrm{x}$.

2. A regular polygon of $n$ sides has each exterior angle equal to $45^{\circ}$. Find the value of $n$.

3. The sum of 6 and one-third of $x$ is one more than twice $x$. Find $x$

4. An arc of a circle subtends an angle of $60^{\circ}$ at the centre. If the radius of the circle is $3 \mathrm{~cm}$, find, in terms of $\pi$, the length of the arc.

5. A boy looks through a window of a building and sees a mango fruit on the ground 5om away from the foot of the building. If the window is $9 \mathrm{~m}$ from the ground, calculate, correct to the nearest degree, the angle of depression of the mango from the window. 